\title{
Day Care Centers for Children in Karachi City: A Mapping Study
}

\author{
Samina Rauf* \\ Sumera Ishrat ${ }^{* *}$
}

\begin{abstract}
Many parents send their pre-school aged children to daycare services. Generally, children spend their time in daycare from the age of 3 months to 5 years. Various daycare centers are operating in Karachi. This researcher is exploratory and was focused on gathering information about the care quality standards of daycare centers. Different factors, which include institution type, operational timings, building structure and capacity, financial sources, workforce competency, service delivery mechanism (use of equipment), the behavior of staff, amenities available, hygiene management, and perception of daycare service providers have been analyzed in this research.
\end{abstract}

Key Words: Daycare centers, Services delivery mechanism, Financial sources, Staff competencies, and Hygiene management

\footnotetext{
*Assistant Professor, Department of Social Work, University of Karachi. email: sam.rauf@uok.edu.pk

**Assistant Professor, Department of Social Work, University of Karachi. email: sumeraishrat@uok.edu.pk
} 


\section{Introduction}

In the past few decades, the notable increase has been observed in the participation of pre-school aged children in the daycare arrangements. These children are managed and cared in a nonparental environment where staff looks after the children for a specific duration. In a study highlighted that nearly two-thirds of young children attend child care and spend more than 30 hours a week in daycare centers ${ }^{1}$. Children are sent to daycare services soon after childbirth and spend 3 to 5 years in such settings. NICHD in their study of 'Early Child Care' reported that children enter the daycare center at the age of three months. More than $50 \%$ of the time daily is spent in a daycare center in a non-parental care environment and on average interacts with three caregivers. ${ }^{2}$

Care to set for pre-school aged children can be classified into three categories: 1) Relative care; 2) Daycare center; 3) and family-based arrangements. Childcare is considered to be a regular part of life, especially in urban areas ${ }^{3}$. The concept evolved rapidly in western countries where generally both parents spend their day time at work and therefore send their children to daycare services. Generally, more than $75 \%$ of females who work send their babies to daycare centers. ${ }^{4}$ In a child's daycare setting, the concept of education, healthcare, personal development, and socialization is often diffused. Facilities available in daycare centers differ to a great extent.

There has been a notable increase in female employment in the last two decades in Pakistan. The trend of working females is increasing rapidly and females now have representation in nearly every industry. This has led to an increased reliance on child daycare service center for taking care of infants and young babies. Children are sent to daycare centers until women spend their time at the workplace. Children spend a significant duration of their initial development stages in daycare centers; therefore, it is necessary to assess the role of caregivers in shaping children's behavior; also, assessment of risks posed by daycare centers to child health and development.

An increase in female employment has led to an increase in non-parental care services. ${ }^{5}$ Therefore, this has raised the interest of researchers, psychologists, and policymakers associated to understand the implication of caregiving services in child development and the risk posed by such institutions to child health, safety, and personality development.

The present study was specifically focuses on the following major aspects of Daycare centers operating in Karachi city:

- Employee's education and professional approach

- amenities

1 NICHD. Does the amount of time spent in child care predict socio-emotional adjustment during the transition to kindergarten? Child Development, 74. 2003. 976-1005.

2 NICHD. Study of Early Child Care and Youth Development: Findings for Children up to Age 41/2 Years.U.S. Department of Health and Human Services. 2006. Retrieved on 23 Oct 2015 from https://www.nichd.nih.gov/publications/pubs/documents/seccyd_06.pdf

3 J. Hill, J. Waldfogel, \& J. Brooks-Gunn, Differential effects of high-quality child care. Journal of Policy Analysis and Management, 21. 2002. 601-627.

4 R. Bernal \& M. Keane, Child care choices and children's cognitive achievement: The case of single mothers. Journal of Labor Economics, 29. 2011. 459-512.

5 P. Auinger, B. P. Lanphear, H. J. Kalkwarfn \& M.E. Mansour, Trends in otitis media among children in the United States. Journal of Pediatrics,112. 2003. 514-520. 
- Health and safety management

\section{Literature Review}

Increased participation of women in a household earning sharing has created pressure on them to maintain balance in work life, social life, and maternal life. To maintain balance, females started considering the placement of children in daycare centers during their pre-school age. Daycare services not only create convenience for parents (in families where both partners are working) but also created a boom in the demand for caregiving services. However, it also raised concerns related to parental employment, social expectations of parenthood, and fulfillment of the needs of infants and pre-school age children. ${ }^{6}$ Various researches have conducted to assess the effectiveness of child care centers and its role in children's development wellbeing and consequences. ${ }^{7}$ The mother-child relationship is very important in the early childhood age and is regarded as a foundation of a child's mental and psychological development. ${ }^{8}$ Different researchers have studied this concept to validate the impact on non-parental care on child development factors. Non-parental child care may not only impact the mental and psychological development of a child but also can have a substantial effect on the natural traits of a mother for child care. Research conducted by NICHD reported that prolonged separation from a child harms the mother's ability for sensitive responses towards their child, especially when they are in infant stages. Such behavioral traits also affect the child's expectation of maternal responsiveness. In this study, it was identified that detachment from parents in the first year of life increases the attachment insecurity among children. ${ }^{9}$

NICHD study highlighted that also $9 \%$ of children received enriched positive care in daycare centers. Around $30 \%$ of children received a fair amount of care; $53 \%$ received some sort of positive caregiving. However, an $8 \%$ sample selected for the study did not receive any form of positive caregiving which is essential for child development in daycare settings in the first 3 years of life. High-quality care in caregiving settings tends to improvise the literacy and numeracy skills of children. It also examined the time spent by children in daycare settings for various age groups. As per the study findings, $27 \%$ children between the age of 3 months and 1.5 years spend more than 30 hours in daycare; $44 \%$ children between the age of 1.5 years and 3 years spend more than 30 hours in daycare, and $50 \%$ children between the age of 3 and 4.5 years spend more than 30 hours in daycare settings. ${ }^{10}$

Quality of daycare services can be measured by various methods which include processes assessment, monitoring safety, and health provisions, and by assessing caregiver

6 S. Loeb, B. Fuller, S. Kagan \& B. Carrol, Child care in poor communities: Early learning effects of type, quality, and stability. Child Development, 75. 2004. 47-65.

7 E. Peisner-Feinberg, M. Burchinal, R. Clifford, M. Culkin, C. Howes, S. Kagan \& N. Yazejian, The relation of preschool childcare quality to children's cognitive and social development trajectories through second grade. Child Development, 72.2001. 1534-1553.

8 R. Gordon, R. Kaestner \& S. Korenman, The effects of maternal employment on child injuries and infectious disease. Demography, 44. 2007. 307-333.

9 NICHD. Child care and family predictors of preschool attachment and stability from infancy. Developmental Psychology, 37.2001 (a). 847-862.

10 NICHD. Study of Early Child Care and Youth Development: Findings for Children up to Age 41/2 Years. U.S. Department of Health and Human Services. 2006. Retrieved on 23 Oct 2015 from https://www.nichd.nih.gov/publications/pubs/documents/seccyd_06.pdf 
characteristics. ${ }^{11}$ NICHD study identifies that group size, the ratio of children to staff, education level of services provider, specialized training in the daycare services field are important factors in defining the daycare services quality level. ${ }^{12}$ Elicker, Fortner, and Noppe (1999) in their study reported that children group size predicts caregiver behavior when children to staff ratio are controlled $^{13}$. Caregivers tend to be less restrictive and more responsive when there are fewer children in classrooms. Formal education of staff in the field of daycare and specialized training is associated with quality of care. ${ }^{14}$ Staff members, who have relevant education and training tend to be supportive, display warm behavior and are more organized in developing material and arranging activities that are appropriate for children of related age groups.

Children health and safety concept is also very important in the context of daycare services. It has been identified that children in a large group setting are more likely to get infected and have exposure to various diseases. ${ }^{15}$ The intensity of health risks increases in which children are at an early age. However, Auinger et al. (2003) in their research reported that children prone to diseases in their early ages are likely to build immunity against various diseases, which helps in minimizing the impact of health-related diseases in school-age years. Considering the high cost associated with daycare services and the impact of these services on the child's personality, mental development and exposure to health risks, many studies have tried to understand this phenomenon. ${ }^{16}$

Many parents send their preschool-aged children to daycare services. Generally, children spend their time in daycare from the age of 3 months to 5 years. ${ }^{17}$ The findings indicated that children who spent their major part of infancy and pre-school age in daycare centers are more likely to undergo from respiration, ear, and eye diseases. Whereas the possibility to have serious injuries are very least. Also, if any health effect is observed in the first year of life are likely to fade over time until the child reaches the age of 3. This improvises the immunity of children to fight against various diseases as well; along with no major observances on other child development areas. $^{18}$

Another domain in the context of daycare services is related to children's personalities, including mental, behavioral, psychological and social development. Some of the notable components adjacent to these factors include self-control, conformity, adherence to rules, peer interactions, love and care, and a sense of security. These factors are very important in the early school-age of

11 D. Blau, The effects of child care characteristics on child development. Journal of Human Resources, 34. 1999. $786-822$.

12 NICHD, Study of Early Child Care and Youth Development: Findings for Children up to Age 41/2 Years.U.S. Department of Health and Human Services. 2006. Retrieved on 23 Oct 2015 from https://www.nichd.nih.gov/publications/pubs/documents/seccyd_06.pdf.

13 J. Elicker, W. Fortner \& I. Noppe, The Context of Infant Attachment in Family Child Care. Journal of Applied Developmental Psychology, 20.1999. 319-336.

14 NICHD, Study of Early Child Care and Youth Development: Findings for Children up to Age 41/2 Years.U.S. Department of Health and Human Services. 2006. Retrieved on 23 Oct 2015 from https://www.nichd.nih.gov/publications/pubs/documents/seccyd_06.pdf

15 NICHD , Child Care and Common Communicable Illnesses. Archives of Pediatric Adolescent Medicine, 155, 2001(b). 481488.

16 P Auinger, B. P. Lanphear, H. J. Kalkwarf \& M. E. Mansour, Trends in otitis media among children in the United States. Journal of Pediatrics, 112. 2003. 514-520.

17 NICHD, Child care and family predictors of preschool attachment and stability from infancy.Developmental Psychology, 37.2001(a). 847-862.

18 D. Blau, D, The effects of child care characteristics on child development. Journal of Human Resources, 34. 1999. $786-822$. 
children and help them achieve good results and display better performance. ${ }^{19}$ Noteworthy impact of daycare services and detachment from parents for a greater duration in the early stages of life affect the behavioral and mental functioning in the later part of life. ${ }^{20}$ NICHD study identified that children who are brought up in daycare centers tend to have poor peer interaction and exhibit behavioral problems and disassociation in social circles, which does not serve the concept of exemplary natural and required behavioral traits development in the child. Disruptive behavioral formation in the early stages of life tends to exist throughout childhood. ${ }^{21}$

Researchers have also focused on understanding the implication of non-parental care impact on a child's mental development. Studies have shown a significant association between the two factors and highlight that child's mental development is affected to some extent if they spend their time in non-parental care settings in the initial 3 years of birth. However, in some studies, no significant impact has been identified. ${ }^{22}$ Several studies have also marked that the highquality daycare settings resultant in positive outcomes when teachers in these center have cognitive stimulating interactions with every child. Loeb et al. (2004) in their study identified that upbringing in care tends to have a positive impact on the personality development of economically disadvantaged children. Personality traits developed as an outcome of upbringing in daycare centers tend to exist through the school-age of children. ${ }^{23}$ Belsky et al. (2007) have also reported similar findings for the positive impact of non-parental care in the mental development of children. ${ }^{24}$

Parents who send their children to daycare centers tend to have a high preference towards their work-life; hence, balance their need by sending their children to daycare centers for provision of required services in the day time. ${ }^{25}$ This creates lesser problems for them in terms of tackling the work life-related issues while ensuring proper child care. Also, this enables them to have high value for children's socialization beginning at an early age. Moreover, non-parental care setting also enhances the mental abilities and helps children improvise on the skills which they lack, such as communication and openness. ${ }^{26}$ Therefore, parents intentionally send their children to daycare centers to achieve these benefits. Therefore, it can be inferred that child's well-being and development are based on the decision of parents for child care. One important thing in the child care context is to consider the differences across families and children; otherwise, studies may provide unreliable evaluations for the impact of non-parental care centers utilization.

19 R Bernal \& M. Keane, Child care choices and children's cognitive achievement: The case of single mothers. Journal of Labor Economics, 29. 2011. 459-512.

20 C. Raver, Emotions matter: Making the case for the role of young children's emotional development for early school readiness. Social Policy Report of the Society for Research in Child Development, 16. 2002. 1-20.

21 J. Belsky, D. L. Vandell, M. Burchinal, K. A Clarke-Stewart, K. McCartney, M. T. Owen,. Are there long-term effects of early child care? Child Development, 78. 2007. 681-701.

22 D. Blau, The effects of child care characteristics on child development. Journal of Human Resources, 34.1999. 786-822.

23 S. Loeb, B. Fuller, S. Kagan \& B. Carrol, Child care in poor communities: Early learning effects of type, quality, and stability. Child Development, 75. 2004. 47-65.

24 J. Belsky, D. L. Vandell, M. Burchinal, K.A. Clarke-Stewart, K. McCartney \& M. T Owen, Are there long-term effects of early child care? Child Development, 78. 2007. 681-701.

25 R. Gordon, R. Kaestner \& S. Korenman, The effects of maternal employment on child injuries and infectious disease. Demography, 44. 2007. 307-333.

26NICHD, Does the amount of time spent in child care predict socio-emotional adjustment during the transition to kindergarten? Child Development, 74. 2003. 976-1005. 


\section{Conceptual Framework}

The below-mentioned diagram displays the conceptual framework that has been used in this research study. Institution type, operational timings, building structure and capacity, financial sources, workforce competency, service delivery mechanism (use of equipment), the behavior of staff, amenities available, hygiene management, and perception about caregiving centers have been analyzed in this research. All these factors in combination define the quality of service provided in the caregiving center of Karachi, Pakistan.

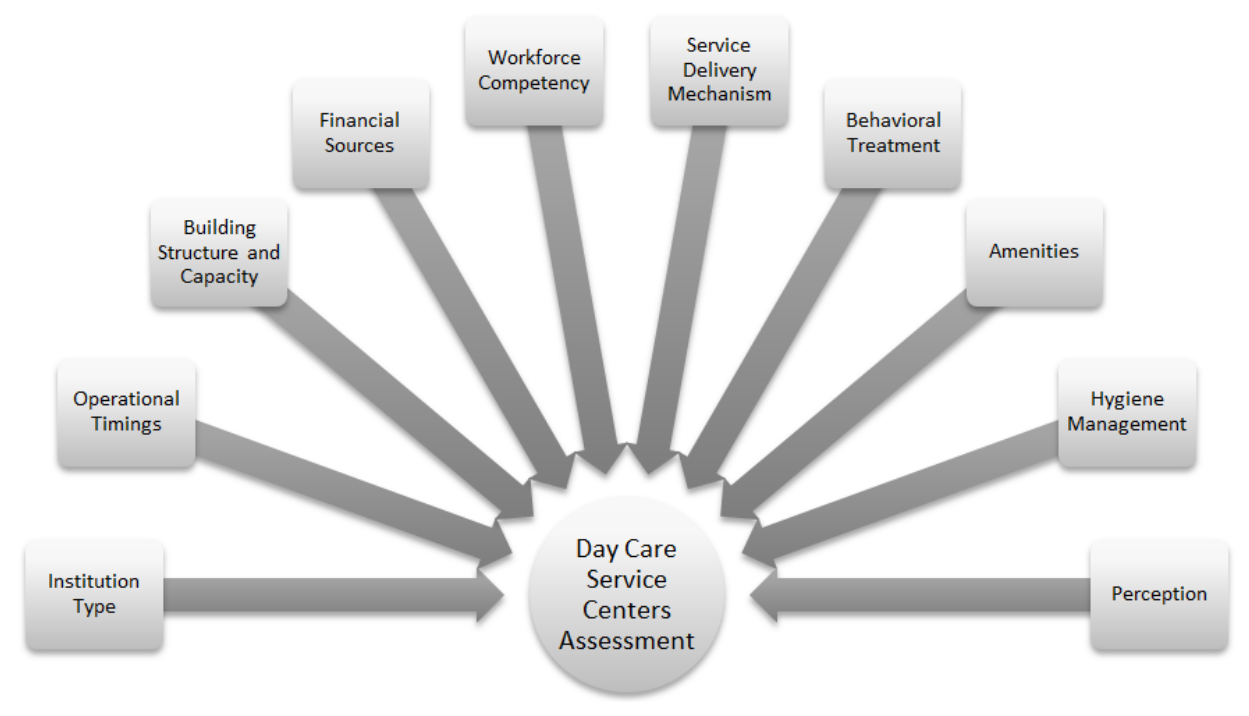

Figure 1: Conceptual Framework

\section{RESEARCH METHODOLOGY}

In the present study, the data was collected using the 'convenience sampling' method which is a non-probability based sampling technique. The scope of the data collection was limited to Karachi city.

Respondents of the research included operational staff of the daycare centers, founding members, and management executives. No incentives have been used to encourage participation in the survey. It was solely based on the respondent's interest to participate in the research to share their input.

Primary research methodology has been used for data collection in this research. A questionnaire was developed to gather information about services offered in a daycare center and facilities available in daycare centers of Karachi. A hard copy questionnaire was distributed to the members/staff of daycare centers for data collection. The questionnaire was self-administered and minimal involvement was required for providing an understanding of questions in a few instances. It comprised 31 items which were mainly focused on the type of institution, funding source, safety and security, type of services offered, staff competency, amenity services, staff behavior, disciplined environment, and conforming to hygiene practices. 
More than 50 daycare centers were approached to participate in the survey. However, only 37 agreed to participate in the survey. Since this is exploratory research, therefore, a sample of greater than 30 is considered appropriate for preliminary analysis and findings.

\section{FINDINGS OF THE STUDY}

Table 1: Primary Information of Institutions

\begin{tabular}{|c|c|c|c|c|c|}
\hline Institution Type & $F$ & $\%$ & Services Type & $F$ & $\%$ \\
\hline Private & 34 & $92 \%$ & Recreational & 11 & $30 \%$ \\
\hline Semi-Private & 1 & $3 \%$ & Educational & 9 & $24 \%$ \\
\hline Other & 2 & $5 \%$ & Both & 17 & $46 \%$ \\
\hline Total & 37 & $100 \%$ & Total & 37 & $100 \%$ \\
\hline Registration Act & $F$ & $\%$ & Timings & $F$ & $\%$ \\
\hline Society Act & 1 & $3 \%$ & $8 \mathrm{am}-2 \mathrm{pm}$ & 8 & $22 \%$ \\
\hline Organization Act & 24 & $65 \%$ & $8 \mathrm{am}-5 \mathrm{pm}$ & 17 & $46 \%$ \\
\hline Trust Act & 4 & $11 \%$ & $2 \mathrm{pm}-8 \mathrm{pm}$ & 7 & $19 \%$ \\
\hline Welfare Act & 2 & $5 \%$ & 7 am-7 pm & 5 & $14 \%$ \\
\hline NGO Act 1961 & 6 & $16 \%$ & Total & 37 & $100 \%$ \\
\hline Total & 37 & $100 \%$ & Weekly Off & $F$ & $\%$ \\
\hline Ownership Classification & $F$ & $\%$ & 1 day off & 16 & $43 \%$ \\
\hline Rent & 10 & $27 \%$ & 2 days off & 21 & $57 \%$ \\
\hline Trust & 2 & $5 \%$ & Total & 37 & $100 \%$ \\
\hline Own & 23 & $63 \%$ & Rooms in Day Care Center & $F$ & $\%$ \\
\hline Did not answer & 2 & $5 \%$ & 01-May & 26 & $71 \%$ \\
\hline \multirow[t]{3}{*}{ Total } & 37 & $100 \%$ & 06-Oct & 9 & $24 \%$ \\
\hline & & & Nov-15 & 2 & $5 \%$ \\
\hline & & & Total & 37 & $100 \%$ \\
\hline
\end{tabular}

The sample selected for the study mainly comprised of private institutions, which had a representation of $92 \%$ in the entire sample size. Mostly $(65 \%)$ were registered under the Organization Act whereas It was identified that $63 \%$ of them are operational from an owned building. $46 \%$ of these daycare centers are providing both services, i.e. recreational as well as educational services and are operational for the entire day, i.e. 8 am-5 pm. 57\% of daycare centers reported having 2 days off in a week, i.e. Saturday and Sunday. The majority of the center has the capacity of up to 5 rooms, which accounted for $70 \%$ sample selected in this research. 
Table 2: Funding Source

\begin{tabular}{|c|c|c|}
\hline Sources & $\mathrm{f}$ & $\%$ \\
\hline Funds/Donations & 2 & $5 \%$ \\
\hline Govt. funds & 2 & $5 \%$ \\
\hline Fees & 33 & $90 \%$ \\
\hline Total & 37 & $100 \%$ \\
\hline
\end{tabular}

The fee is the major source of funding for daycare centers. Respondents were also asked about the fees that they charge from their customers. It was identified that fees varied from institution to institution and ranged from 5000-20000 per month based on the services that are provided. Only $10 \%$ of daycare centers included in the study were running on donations or funds from the government.

Table 3: Fee Discount

\begin{tabular}{|c|c|c|}
\hline Discounts Provided & f & $\%$ \\
\hline Yes & 21 & $57 \%$ \\
\hline No & 16 & $43 \%$ \\
\hline Total & 37 & $100 \%$ \\
\hline
\end{tabular}

$57 \%$ of institutions provided Fee discounts while the rest did not report having any such practices, therefore, they charged the full fee.

Table 4: Workforce Competency

\begin{tabular}{|c|c|c|}
\hline Trained for Regular Duties & Frequency & $\%$ \\
\hline Yes & 35 & $95 \%$ \\
\hline No & 2 & $5 \%$ \\
\hline Total & 37 & $100 \%$ \\
\hline Trained for Emergency Situations & Frequency & $\%$ \\
\hline Yes & 35 & $95 \%$ \\
\hline No & 2 & $5 \%$ \\
\hline Total & 37 & $100 \%$ \\
\hline
\end{tabular}

Nearly, every daycare center included in the study considered employee training to be an important factor. 95\% had trained employees for managing the children in daycare centers. These employees were also trained to handle emergencies. The remaining 5\% institution reported an area of improvement for employees and stated that actions are being taken to train their employees to handle emergencies as well as regular duties. 
Table: 5: Use of Equipment in Service Delivery

\begin{tabular}{|c|c|c|}
\hline Equipment Available & $\mathrm{f}$ & $\%$ \\
\hline Yes & 22 & $59 \%$ \\
\hline No & 1 & $3 \%$ \\
\hline Did not answer & 14 & $38 \%$ \\
\hline Total & 37 & $100 \%$ \\
\hline Objects Available for Teaching & $\mathrm{f}$ & $\%$ \\
\hline Yes & 19 & $52 \%$ \\
\hline No & 2 & $5 \%$ \\
\hline Did not answer & 16 & $43 \%$ \\
\hline Total & 37 & $100 \%$ \\
\hline Toys for All Ages & Frequency & $\%$ \\
\hline Yes & 33 & $89 \%$ \\
\hline No & 4 & $11 \%$ \\
\hline Total & 37 & $100 \%$ \\
\hline Area Safe/Secure & $\mathrm{f}$ & $\%$ \\
\hline Yes & 36 & $97 \%$ \\
\hline No & 1 & $3 \%$ \\
\hline Total & 37 & $100 \%$ \\
\hline
\end{tabular}

Daycare centers service delivery is also dependent on the use of equipment for training, education, learning, entertainment, and recreational activities. 59\% of institutes claimed to have a sufficient quantity of equipment is available. Similarly, $52 \%$ of daycare centers mentioned having specific objects that are used for teaching purposes. $89 \%$ of centers had toys for children of every age group. Moreover, $97 \%$ of daycare centers had reported that they have a safe and secure playing environment for the children which reflected their due consideration on the safety of playing the environment.

Table 6: Behavioral Treatment

\begin{tabular}{|c|c|c|}
\hline Way of Dealing & $\mathrm{f}$ & $\%$ \\
\hline Professional & 24 & $65 \%$ \\
\hline Loving Behavior & 13 & $35 \%$ \\
\hline Total & 37 & $100 \%$ \\
\hline
\end{tabular}

$65 \%$ of institutes mentioned that they have a professional decorum of dealing with children. Staff members abide by strict disciplinary procedure and children are also expected to follow the norms. However, 35\% mentioned that they have a loving behavior approach towards managing children and providing their daycare services to children. They believed that a loving behavior approach inculcates an open learning environment and encourages young children to try new things and grow better with an open mind. 
Table 7: Amenities provided in Centers

\begin{tabular}{|c|c|c|}
\hline Type of Meal Served & f & $\%$ \\
\hline Breakfast & 7 & $19 \%$ \\
\hline Milk & 4 & $11 \%$ \\
\hline Snacks & 5 & $14 \%$ \\
\hline All of them & 21 & $56 \%$ \\
\hline Total & 37 & $100 \%$ \\
\hline Medical Facilities Available & $\mathrm{f}$ & $\%$ \\
\hline Yes & 32 & $86 \%$ \\
\hline No & 5 & $14 \%$ \\
\hline Total & 37 & $100 \%$ \\
\hline Generator Available & $\mathrm{f}$ & $\%$ \\
\hline Yes & 13 & $35 \%$ \\
\hline No & 2 & $5 \%$ \\
\hline Did not answer & 22 & $60 \%$ \\
\hline Total & 37 & $100 \%$ \\
\hline
\end{tabular}

Every daycare center included in the study provides a meal to children. Breakfast, milk, and snacks, all these items are served in $56 \%$ centers. Remaining $44 \%$ of centers provide only one of these items. $86 \%$ of centers have proper medical facilities available. Some daycare centers reported having a dedicated clinic with the capability to provide first level medical services in case of an emergency whereas $87 \%$ of daycare centers have generator facilities available to ensure a continuous supply of electricity.

Table 8: Hygiene Management

\begin{tabular}{|c|c|c|c|c|}
\hline $\begin{array}{c}\text { Duration of Changing } \\
\text { Diapers }\end{array}$ & $\mathrm{f}$ & & \multicolumn{2}{|l|}{$\%$} \\
\hline After 1 hour & 3 & & \multicolumn{2}{|l|}{$8 \%$} \\
\hline After 4 hours & 24 & & \multicolumn{2}{|l|}{$65 \%$} \\
\hline After 6 hours & 3 & & \multicolumn{2}{|l|}{$8 \%$} \\
\hline As and when needed & 7 & & \multicolumn{2}{|l|}{$19 \%$} \\
\hline Total & 37 & & \multicolumn{2}{|l|}{$100 \%$} \\
\hline \multirow{2}{*}{ Hygiene Management Practices } & \multicolumn{2}{|c|}{$\mathrm{f}$} & \multicolumn{2}{|c|}{$\%$} \\
\hline & Yes & No & Yes & No \\
\hline Staff Follow Hygiene Rules & 37 & - & $100 \%$ & - \\
\hline Children Wash Hands Before Meals & 37 & - & $100 \%$ & - \\
\hline
\end{tabular}

Hygiene is an important element in daycare center services. To promote better health of children, it is important to maintain hygiene standards in the centers. It was identified that in $65 \%$ of centers, diapers are changed after 4 hours as a set of practices. $100 \%$ hand hygiene rate is reported for the sample included in the study. Every staff member follows hygiene rules; children are also asked to wash hands before having a meal. 
Table 9: Perception of Private vs. Government-Owned Day Care Centers

\begin{tabular}{|c|c|c|}
\hline Comparison & f & $\%$ \\
\hline Private owned centers are better & 18 & $49 \%$ \\
\hline Government-owned centers are better & 3 & $8 \%$ \\
\hline Prefer not to answer & 16 & $43 \%$ \\
\hline Total & 37 & $100 \%$ \\
\hline
\end{tabular}

Half of the institutions reported private daycare centers to have better services standard as compare to government-owned daycare centers due to various reasons, which include service standard, staff competency, strong conformity to hygiene practices, furnished buildings, and amenities available. However, $43 \%$ preferred not to answer this question and skipped it during the survey. Only $8 \%$ considered government and private-owned daycare centers to be of equal standard.

\section{Discussion}

An increase in female employment has led to an increase in non-parental care services (Auinger et al., 2003). Many parents send their pre-school aged children to daycare services. Generally, children spend their time in daycare from the age of 3 months to 5 years. In this research, daycare services that cover employee professionalism, education, amenities, health, and safety management have been assessed for the centers operating in Karachi.

Results present valuable insights about the current standards of the daycare centers operating in Karachi. This information would be valuable to policymakers, healthcare professionals, and social activists in making guidelines and setting benchmarks for the quality daycare services delivery. One interesting finding from the results is that majority of institutions operating in Karachi are private in nature. Therefore, government bodies have very limited control over the policies and management structure of private institutions. Although, government institutions make policies to regulate the practices of private-owned institutions, however, such institutions do not fully comply with regulations. Approximately two-thirds of institutions have been formed under the organization act. Organization act provides considerable freedom to institutions to form their own policies and regulations for operating procedures.

In terms of purpose, all types of daycare service centers have been operating in Karachi. These include ones operating only for educational purposes, operating only for recreational purposes, and ones operating for educational as well as recreational purposes. More than half of these daycare centers are operating for the entire day, i.e. morning till evening. Mainly, parents (especially females) go to work in the morning and return in the evening after $5 \mathrm{pm}$. Therefore, they send their children to daycare centers for proper care and learning purposes. Parents leave their children in caregiving centers when they are going for work, mainly before 9 am and pick their children when going home from work, mainly after $5 \mathrm{pm}$. Therefore, children spend a significant portion of their pre-school age in daycare centers. Therefore, their upbringing is influenced by their interaction with staff in daycare centers.

For building standards, the majority of these centers are operating in owned buildings; founders established these centers in their owned property. More than $2 / 3$ institutions included in the study 
had room capacity between 1-5 rooms. Therefore, it is noticeable here that in order to establish a daycare center, no major investment is required to acquire a property. Establishing the day centers in rented space and then utilizing the funds generated through fees can be used to expand the building premises. The majority of daycare centers reported fees to be the main funding source for running the caregiving centers. During an interview with caregiving center staff and founding members, it was identified that fees range from 3000 to 15000 per month based on the quality of services delivered and the market value of the caregiving center in Karachi. Also, nearly 4/5 institution does not consider the fees to be high because of services provided by them. However, if some parents consider the fees to be high, nearly half of the institutions have a discount policy to accommodate people from different income groups.

Workforce competency is very important for delivering quality services. Employees' skills, competencies, and abilities are profound to child development from an early age. Children's interaction with staff and their learning is dependent on the employee experience and knowledge level. Therefore, there is an intense need to have a trained workforce for managing business operations. Nearly, every institution included in the study considered its employees to be trained for regular duties as well as handling emergency situations. However, no assessment was done in this research to evaluate the competencies of employees for performing their regular duties. Approximately, 2/3 institutions have a defined code of conduct which is followed by employees while dealing with children. This is regarded as professional behavior in this research paper. Whereas, 1/3 institutions reported having a loving behavior approach towards children. However, no significant difference has been reported between the two approaches with respect to children's happiness level with staff. Therefore, institutions can adapt any of these approaches, which would provide similar results in terms of service delivery and derived satisfaction level.

Daycare centers service delivery is also dependent on the use of equipment for training, education, learning, entertainment, and recreational activities. It is important for policymakers and government regulating bodies to ensure that caregiving centers have an adequate quantity available of equipment that is used for education, learning, entertainment, and recreational activities. During data collection, many daycare centers did not provide an answer when asked for use of appropriate equipment for the above-mentioned reasons.

The service quality of caregiving centers is also judged on the basis of amenities available for children. These include giving a meal to children, medical facilities, first aid facilities, dedicated areas for sports, and other equipment such as a generator for standby electricity. The absence of these amenities may pose health and safety risks for children. $13 \%$ of respondents mentioned that they do not have a generator available in their daycare center and are relying on local electricity corporation for this purpose. Considering the excessive load-shedding problem in Karachi for the past 8-10 years, which sometimes may exceed up to the entire day, is a significant point of concern for caregiving institutions service quality.

Hygiene is an important element in daycare center services. In order to promote better health of children, it is important to maintain hygiene standards in the centers. Nearly every daycare center reported that they conform to hygiene practices, which include regularly changing diapers of children, hand washing before eating meals, staff following hygiene rules. This shows that caregiving centers management understands the need for hygiene management concerning the well-being of children. 


\section{Conclusion}

Many parents send their pre-school aged children to daycare services. Various daycare centers are operating in Karachi. Different factors, which include institution type, operational timings, building structure and capacity, financial sources, workforce competency, service delivery mechanism (use of equipment), the behavior of staff, amenities available, hygiene management, and perception about caregiving centers have been analyzed in this research. Results showed that daycare centers are conforming to hygiene standards, have trained staff, have medical facilities, and other amenities available for children. Employees have a professional and loving behavior towards children which has resulted in the satisfaction of children with staff. In addition to that, they use the equipment for learning and recreational activities of children. However, there is a considerable room still available for improvement of caregiving service quality standards, which is identified in the recommendations section.

\section{Recommendations}

In this research, service quality factors of caregiving centers have been assessed. This research can be used as an initial framework in establishing policies and regulations for the daycare centers operating in Pakistan. Based on the analysis, the following recommendations are proposed for improving the service quality standards of daycare centers:

- All caregiving centers must have medical facilities and conduct regular training sessions of their employees to handle emergency situations.

- Daycare centers, whether operating in rented or owned space, must adhere to safety standards which are essential for minimizing the risk and ensuring the safety of the children and employees.

- The government must provide subsidies and allocate special funds for parents who are unable to afford caregiving services due to high fees. Also, the government can use this fund to improvise the level of services delivered through employee training and doing regular standard checks.

- All caregiving institutions must have the required equipment available for teaching, learning, and recreational activities. The government sets the benchmarks and list of equipment that should be in place for children in caregiving centers to ensure the optimum level of service quality.

- Health and safety department should conduct regular monitoring rounds to ensure that daycare centers conform to hygiene practices; also, training sessions must be conducted for parents and caregiving centers' staff awareness.

\section{Future Research}

This research paper presented an exploratory analysis of the services offered in daycare centers operating in Karachi. However, this research does not cover the aspect of the implications of caregiving services on the mental and physical development of children. Therefore, in future research, researchers can focus on assessing the impact of caregiving service quality and child development. Also, how do these factors vary across the region, i.e. in other cities of Pakistan? 
Day Care Centers for Children in Karachi City: A Mapping Study

In addition, parents' education level, income level, other demographic characteristics, and cultural influence on utilizing caregiving services would be important to assess. 


\section{References}

Auinger, P., Lanphear, B. P., Kalkwarf, H. J.,\& Mansour, M.E., Trends in otitis media among children in the United States. Journal of Pediatrics, 112. 2003. 514-520.

Belsky, J., Vandell, D. L., Burchinal, M., Clarke-Stewart, K. A., McCartney, K., Owen, M. T. Are there long-term effects of early child care? Child Development, 78. 2007. 681-701.

Bernal, R. \& Keane, M. Child care choices and children's cognitive achievement: The case of single mothers. Journal of Labor Economics, 29. 2011. 459-512.

Blau, D. The effects of child care characteristics on child development. Journal of Human Resources, 3.1999. 786-822.

Deming, D. Early childhood intervention and life-cycle skill development: Evidence from Head Start. American Economic Journal: Applied Economics, 1. 2009. 111-134.

Elicker, J., Fortner, W, \& Noppe, I. The Context of Infant Attachment in FamilyChild Care.Journal of Applied Developmental Psychology, 20. 1999. 319-336.

Gordon, R., Kaestner, R., \&Korenman, S. The effects of maternal employment on child injuries and infectious disease.Demography, 44. 2007. 307-333.

Hill, J., Waldfogel, J., \& Brooks-Gunn, J. Differential effects of high-quality child care. Journal of Policy Analysis and Management, 21. 2002. 601-627.

Loeb, S., Fuller, B., Kagan, S. \& Carrol, B. Child care in poor communities: Early learning effects of type, quality, and stability. Child Development, 75. 2004. 47-65.

NICHD (2001c). Child care and children's peer interaction at 24 and 36 months: The NICHD study of early child care. Child Development, 72. 2001 (c). 1478-1500.

NICHD (2003). Does the amount of time spent in child care predict socio-emotional adjustment during the transition to kindergarten? Child Development, 74. 2003. 976-1005.

NICHD Study of Early Child Care and Youth Development: Findings for Children up to Age 41/2 Years.U.S. Department of Health and Human Services.2006. Retrieved on 23 Oct 2015 from https://www.nichd.nih.gov/publications/pubs/documents/seccyd_06.pdf

NICHD. Child Care and Common Communicable Illnesses. Archives of Pediatric Adolescent Medicine, 155.2001(b). 481-488.

NICHD. Child care and family predictors of preschool attachment and stability from infancy. Developmental Psychology, 37. 2001a. 847-862. 
Peisner-Feinberg, E., Burchinal, M., Clifford, R., Culkin, M., Howes, C., Kagan, S., \& Yazejian, N. (2001).The relation of preschool child-care quality to children's cognitive and social development trajectories through second grade. Child Development, 72. 2001. 1534-1553.

Raver, C. (2002). Emotions matter: Making the case for the role of young children's emotional development for early school readiness. Social Policy Report of the Society for Research in Child Development, 16, 2002. 1-20. 